\title{
Elaboração e validação de escala diagramática para quantificação da mancha de ramularia do algodoeiro
}

\author{
Leonardo Angelo Aquino ${ }^{1}$, Paulo Geraldo Berger ${ }^{1}$, Fabrício Ávila Rodrigues², Laércio Zambolim², Juan Felipe Rivera \\ Hernandez ${ }^{1}$, Lucas Mattos Miranda ${ }^{1}$
}

\begin{abstract}
${ }^{1}$ Departamento de Fitotecnia, Universidade Federal de Viçosa, CEP 36570-000, Viçosa, MG; ${ }^{2}$ Departamento de Fitopatologia
Parte da Dissertação de Mestrado do primeiro autor.

Autor para correspondência: Paulo G. Berger. pgberger@ufv.br

Data de chegada: 06/04/2006. Aceito para publicação em: 07/10/2008
\end{abstract}

\section{RESUMO}

Aquino, L.A.; Berger, P.G.; Rodrigues, F.Á.; Zambolim, L.; Hernandez, F.R.; Miranda, L.M. Elaboração e validação de escala diagramática para quantificação da mancha de ramularia do algodoeiro. Summa Phytopathologica, v.34, n.4, p.361-363, 2008

Objetivou-se elaborar e validar uma escala diagramática para avaliar a mancha de ramularia em folhas de algodoeiro com os seguintes níveis de severidade: 0,$05 ; 0,50 ; 1,0 ; 2,0 ; 4,0 ; 8,0 ; 16,0 ; 32,0$ e
67,20. A escala obtida mostrou-se adequada para avaliar a doença aumentando a acurácia e a precisão da avaliação, oferecendo estimativas reproduzíveis da severidade da doença.

Palavras-chave adicionais: severidade, acurácia, precisão, Ramularia gossypii.

\section{ABSTRACT}

Aquino, L.A.; Berger, P.G.; Rodrigues, F.Á.; Zambolim, L.; Hernandez, F.R.; Miranda, L.M. Elaboration and validation of a diagrammatic scale to quantify areolate mildew on cotton. Summa Phytopathologica, v.34, n.4, p.361-363, 2008

This study aimed to elaborate and validate a diagrammatic scale to assess areolate mildew on cotton leaves. The proposed scale showed disease levels of $0.05,0.50,1.0,2.0,4.0,8.0,16.0,32.0$ and $67.20 \%$.
The scale showed to be adequate to evaluate areolate mildew due to an increase in accuracy, precision, and reproductibility during disease evaluations.

Keywords: severity, accuracy, precision, Ramularia gossypii.

Na cultura do algodão são crescentes os problemas com doenças, como, por exemplo, a mancha de ramularia, causada pelo fungo Ramularia gossypii (Speg.) Cif.. Essa doença pode provocar desfolha precoce, diminuindo a produtividade e a qualidade da fibra (4). Os dados sobre quantificação de doenças são importantes no manejo das mesmas no sentido de avaliar diferentes medidas de controle, resistência varietal e teste da eficácia de produtos fitossanitários (2). A utilização de escalas diagramáticas pode reduzir a subjetividade das estimativas de severidade melhorando a acurácia e a precisão da avaliação (5).

Ainda não existe uma escala diagramática definida para quantificação, de forma precisa e acurada, da mancha de ramularia do algodoeiro. Assim, objetivou-se elaborar e validar uma escala diagramática para avaliação da severidade dessa doença.

Foram coletadas 160 folhas de plantas de algodoeiro (variedade Delta Opal) com diferentes níveis de severidade da doença, em experimento instalado no município de Viçosa-MG. As folhas foram fotografadas individualmente e as imagens com resolução de $300 \mathrm{dpi}$ foram transferidas para um microcomputador. Em razão da dificuldade para processamento das imagens e determinação da severidade no programa QUANT (6), devido à similaridade de cores entre os sintomas e algumas partes sadias da folha, foi necessário imprimir as fotos, para que as lesões fossem coloridas com cor distinta das demais cores da folha para facilitar a detecção. A seguir, essas foram escaneadas e processadas no programa QUANT, obtendo-se a severidade real da doença em termos percentuais. A partir da severidade mínima e máxima encontrada nas folhas analisadas e obedecendo a lei de acuidade visual de Weber-Fechner, estabeleceu-se os sete níveis intermediários da doença para compor a escala diagramática.

Realizou-se a validação da escala em duas etapas. Numa primeira, cinco avaliadores com experiência na avaliação de doenças e cinco sem experiência, analisaram as 100 folhas de algodão com diferentes níveis de severidade de ramularia, sem uso da escala diagramática proposta. O grupo de avaliadores considerados com experiência recebeu treinamento prévio na avaliação da ramularia por meio de um arquivo em Power Point ${ }^{\circledR}$ contendo 60 folhas com diferentes níveis de sintomas da doença. Nesse arquivo, em cada slide aparecia a foto e em seguida a severidade correspondente. Na segunda etapa para validação da escala, os mesmos avaliadores analisaram novamente as fotos com auxílio da escala diagramática proposta, realizando-se interpolação para os níveis de doença. Analisou-se ainda a reprodutibilidade das avaliações, comparando-se as severidades estimadas pelos diferentes avaliadores aos pares (5). A partir dos dados de cada avaliador, determinou-se a acurácia e a precisão por meio de regressão linear simples entre a severidade real (variável independente quantificada no programa QUANT) e a severidade estimada (variável dependente), sem e com o uso da escala. A precisão foi avaliada por meio do coeficiente de determinação $\left(\mathrm{R}^{2}\right)$ da regressão e pela variância dos erros absolutos (diferenças entre o valor real e estimado). A acurácia foi avaliada por meio dos parâmetros "a" e "b" da equação de regressão, comparados aos valores 0 e 1 , respectivamente, pelo teste "t" $(\mathrm{p} \leq 0,05)$, sem e 
Tabela 1. Estimativas dos parâmetros de interseção (a), dos coeficientes angulares (b) e coeficientes de determinação ( $\left.R^{2}\right)$ das equações de regressão linear calculadas entre as severidades real e estimada da mancha de ramularia, realizada por avaliadores com e sem experiência, antes e após o uso da escala diagramática.

\begin{tabular}{lllllll}
\hline \multirow{2}{*}{ Avaliadores } & \multicolumn{5}{c}{ Avaliação da Severidade } \\
\cline { 2 - 7 } Experientes & \multicolumn{5}{c}{ sem a escala } & \multicolumn{3}{c}{ com a escala } \\
\cline { 2 - 7 } & $\mathrm{a}$ & $\mathrm{b}$ & $\mathrm{R}^{2}$ & $\mathrm{a}$ & $\mathrm{b}$ & $\mathrm{R}^{2}$ \\
\hline $\mathrm{A}$ & $1,209^{*}$ & 1,021 & 0,922 & 0,519 & 1,023 & 0,968 \\
$\mathrm{~B}$ & $4,066^{*}$ & 0,933 & 0,795 & 0,730 & 1,012 & 0,933 \\
$\mathrm{C}$ & $5,068^{*}$ & 0,965 & 0,809 & $1,395^{*}$ & 1,058 & 0,930 \\
$\mathrm{D}$ & $1,997^{*}$ & 1,026 & 0,796 & 0,398 & 0,981 & 0,882 \\
$\mathrm{E}$ & $1,141^{*}$ & $1,246^{*}$ & 0,838 & $1,076^{*}$ & 0,988 & 0,911 \\
\hline Média & $2,696^{*}$ & 1,038 & 0,832 & 0,824 & 1,012 & 0,925 \\
\hline Inexperientes & & & & & 0,931 \\
$\mathrm{~F}$ & 0,771 & $0,513^{*}$ & 0,755 & $-0,123$ & 0,908 & 0,931 \\
$\mathrm{G}$ & $2,732^{*}$ & $1,358^{*}$ & 0,818 & $2,011^{*}$ & 0,980 & 0,891 \\
$\mathrm{H}$ & $4,121^{*}$ & $1,266^{*}$ & 0,774 & $1,556^{*}$ & $0,877 *$ & 0,898 \\
$\mathrm{I}$ & $5,241^{*}$ & $0,747^{*}$ & 0,724 & 0,969 & 0,889 & 0,908 \\
$\mathrm{~J}$ & $1,074^{*}$ & $0,729^{*}$ & 0,793 & $-0,845$ & 0,918 & 0,898 \\
\hline Média & $2,788^{*}$ & 0,923 & 0,773 & 0,714 & 0,914 & 0,905 \\
\hline
\end{tabular}

* = situações onde o valor da interseção da reta (a) ou o coeficiente angular (b) foi diferente de "0" e "1", respectivamente, pelo teste "t" ao nível de 5\% de probabilidade.

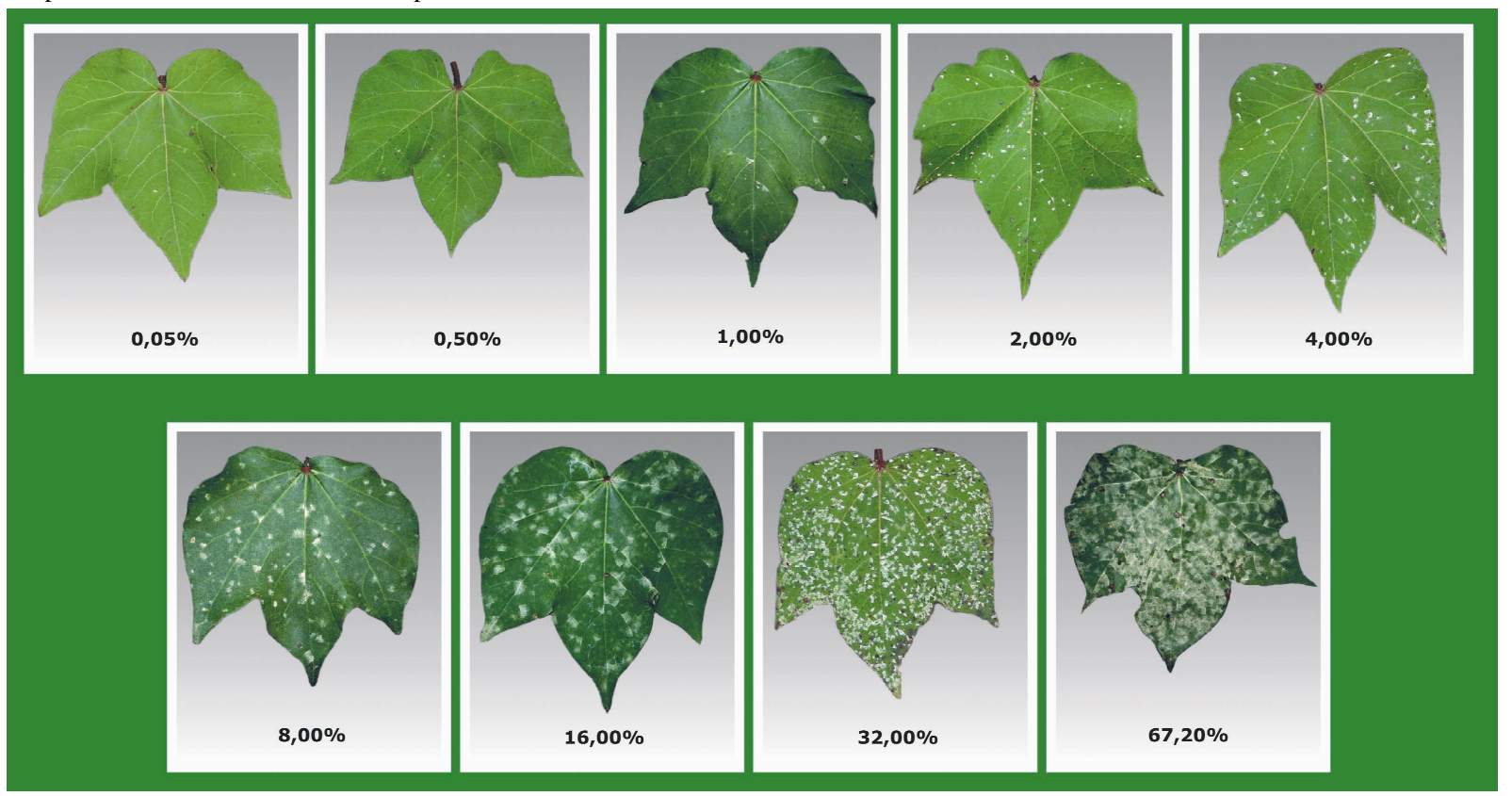

Figura 1. Escala diagramática para avaliação da severidade da mancha de ramularia do algodoeiro.

com uso da escala. As regressões entre a severidade real e a estimada para cada avaliador, bem como entre os avaliadores foram realizadas utilizando-se o programa Microsoft Excel $2000^{\circledR}$ (Microsoft Corporation, 2000).

A escala elaborada tem nove níveis de severidade: 0,$05 ; 0,50 ; 1,0$; 2,$0 ; 4,0 ; 8,0 ; 16,0 ; 32,0$ e 67,20\% (Figura 1). Os dados das análises de regressão dos avaliadores experientes com os inexperientes demonstraram que o treinamento foi efetivo para aumentar a acurácia e a precisão na avaliação da doença. A precisão, a qual indica a confiabilidade nas avaliações da doença, pode ser medida pelo coeficiente de determinação $\left(R^{2}\right)$ entre as severidades real e estimada, enquanto que a acurácia, que se refere à proximidade entre a severidade estimada e a real, pode ser medida comparando-se os parâmetros "a" e "b" com os valores 0 e 1 , respectivamente (1). A avaliação da doença com a escala diagramática aumentou a precisão $\left(\mathrm{R}^{2}\right)$ e a acurácia (intercepto e coeficiente angular da regressão entre severidade real e estimada, com valores significativamente iguais a zero e um, respectivamente), para ambos os grupos (Tabela 1). Esse aumento foi mais expressivo no grupo sem experiência, no qual observou-se um aumento de 77,3\% (sem a escala) para 90,5\% (com escala) na precisão. Ainda houve melhoria da acurácia, pois, em apenas três observações os parâmetros "a" e "b" desviaram da situação ideal $(a=0$ e b $=1)$. No grupo experiente, houve aumento da precisão de $83,2 \%$ para $92,5 \%$ e melhoria na acurácia, já que somente para dois avaliadores o intercepto 
da equação de regressão diferiu de zero.

Independentemente da experiência dos avaliadores, houve aumento da precisão o que foi confirmado pela redução dos erros absolutos e menor dispersão dos dados na regressão (dados não apresentados). A reprodutibilidade, que é a repetibilidade das estimativas, pode ser estimada pela correlação das severidades estimadas pelos avaliadores aos pares. Quando o coeficiente de determinação na comparação de dois avaliadores aproxima-se de $100 \%$, as estimativas dos avaliadores se repetem $(1,3)$. Na regressão das severidades estimadas pelos avaliadores aos pares, foram observados coeficientes de determinação superiores a 78,7\% (dados não apresentados). Em 42 e $75 \%$ das comparações entre avaliadores, o coeficiente de determinação foi superior a 90 e $85 \%$, respectivamente, indicando que as estimativas realizadas com a escala são reprodutíveis.

A escala proposta com níveis de severidade variando de 0,05 a $67,20 \%$, mostrou-se adequada para avaliar a mancha de ramularia do algodoeiro oferecendo estimativas precisas, acuradas e reproduzíveis da severidade, independente da experiência ou não do avaliador com esse patossistema.

\section{AGRADECIMENTOS}

Ao CNPq pela bolsa de mestrado concedida ao primeiro autor e pelas bolsas de produtividade em Pesquisa concedidas aos professores F.A. Rodrigues e L. Zambolim. A FAPEMIG pelo recurso financeiro.

\section{REFERÊNCIAS BIBLIOGRÁFICAS}

1. Belasque Júnior, J.; Bassanezi. R.B., Spósito, M.B.; Ribeiro, L.M.; Jesus Júnior, W.C.; Amorim, L. Escalas diagramáticas para avaliação da severidade do cancro cítrico. Fitopatologia Brasileira, Brasília, v.30, n.4, p.387-393, 2005.

2. Gomes, A.M.A.; Michereff, S.J.; Mariano, R.L.R. Elaboração e validação de escala diagramática para cercosporiose da alface. Summa Phytopathologica, Botucatu, v.30, n.1, p.38-42, 2004.

3. Leite, R.M.V.B.C.; Amorim, L. Elaboração e validação de escala diagramática para mancha de Alternaria em girassol. Summa Phytopathologica, Botucatu, v.28, n.1, p.14-19, 2002.

4. Maranha, F.G.C.B.; Ramalho, M.A.P.; Farias, F.J.C. Estratégias de análise da reação de cultivares de algodoeiro a patógenos. Revista Brasileira Oleaginosas e Fibrosas, v.6, n.2, p.565-575, 2002 .

5. Martins, M.C.; Guerzoni, R.A.; Câmara, G.M.S.; Mattiazzi, P.; Lorenço, S.A.; Amorim, L. Escala diagramática para quantificação do complexo de doenças foliares de final de ciclo em soja. Fitopatologia Brasileira, Brasília, v.29, n.2, p.179-184, 2004.

6. Vale, F.X.R.; Fernandes Filho, E.I.; Liberato, J.R. A software plant disease severity assessment. In: International Congress of Plant Pathology, 8., 2003, Christchurch. Anais. Christchurch: New Zealand, 2003. p.105 (Resumo). 